\title{
$\begin{array}{llllll}R & \text { E } & \text { S } & \text { E } & \tilde{N} & A\end{array}$
}

\section{Hervieu-Léger, Daniéle, 2004, El peregrino y el convertido. La religión en movimiento, Ediciones del Helénico, México.}

$\mathrm{P}$ ara los interesados en el tema de la religión y las formas que adquiere la religiosidad en la actualidad, El peregrino y el convertido. La religión en movimiento es referencia obligada. HervieuLéger se interesa aquí por la singularidad, por el carácter maleable, fluido, disperso de las creencias individuales. Es a partir de la temática del remiendo y de la pulverización de las identidades religiosas, características ahora de las grandes religiones históricas, que propone adentrarse en el paisaje creyente de la modernidad.

$\mathrm{Su}$ reflexión, referida al panorama religioso francés sin dejar de considerar el mismo fenómeno en contextos como el de Estados Unidos, Canadá y otros países de Europa, sugiere que nos enfrentamos a una 'modernidad religiosa' que atañe no sólo a la religión católica, al Islam o el judaísmo: la tendencia general a la subjetivación de las creencias religiosas, a la desregularización y a la opción de los individuos a remendar su sistema de creencias al margen de una definición doctrinal atañe a todas las prácticas religiosas. Prácticas y creencias lanzadas a un perpetuo movimiento, modificadas y combinadas con temas tomados de otras religiones o de corrientes de pensamiento de género místico o esotérico. Ser católico, creer en la reencarnación, en el karma y la astrología es una de tantas formas de ser religioso moderno, porque las combinaciones pueden variar hasta el infinito.
Esta hipótesis la lleva a la revisión de uno de los supuestos que guió los estudios sobre religión durante décadas en el siglo XX: me refiero al de la secularización. En su versión más simple, esta hipótesis preconizaba una relación entre religión y modernidad de exclusión mutua; un encierro de la religión en la esfera privada. Sin embargo, lo que constatamos por doquier es una afirmación de la religión sobre la escena política, una potencialización de las formas tradicionales de religiosidad que parecían condenadas a la extinción por el avance de la racionalidad científica. La idea positivista de que la religión en la modernidad es una forma de experiencia residual condenada a agotarse por el avance de la racionalización técnico-científico de la vida social y la democracia política, es aquí seriamente revisada. Y es que como señaló Gianni Vattimo en Creer que se cree,

...el 'fin de la modernidad' o en todo caso, su crisis ha traído consigo también la disolución de las principales teorías filosóficas que pensaban haber liquidado la religión: el cientificismo positivista, el historicismo hegeliano y, después, marxista. Hoy ya no hay razones filosóficas fuertes y plausibles para ser ateo o en todo caso, para rechazar la religión (Vattimo, 1999: 22). 
Hervieu-Léger discute de nuevo la tesis de Weber sobre la secularización, concepto abarcador e ininteligible si se la separa de los otros supuestos básicos de su obra, es decir: en la modernidad se establece una distinción de las esferas pública y privada; la vida social deja de estar sometida a reglas dictadas por una institución religiosa; las instituciones se diferencian y se separa lo político de lo religioso; el individuo adquiere la autonomía suficiente para intervenir en el mundo, dirigir su vida y cooperar como ciudadano; se opera una adaptación de los medios al fin que se persigue y se pretende que los enunciados explicativos sigan los criterios del pensamiento científico.

La autora nos muestra la imposibilidad de hacer perceptibles las formas de religiosidad modernas si se continúan obviando estos supuestos, si no volvemos a la discusión de las hipótesis que subyacen en la teoría de la secularización. Esta preocupación es, por supuesto, compartida con otros autores.

En Jesús en Disneylandia, Lyons, por ejemplo, critica las teorías de secularización producto de las sociologías racionalistas de mediados del siglo XX, las cuales describen una sociedad regida por principios no religiosos y una religiosidad existiendo de manera marginal, en sociedades modernas inhóspitas para la religión y lo sagrado.

Incluso el supuesto de que una creciente secularización es producto de la modernidad y compañera reciente que inicia su recorrido con el desarrollo del capitalismo ha sido objeto de serias revisiones. En Creer que se cree Gianni Vattimo realiza una reflexión de este problema y plantea que la secularización es condición - no consecuencia- de la modernidad y del mismo cristianismo. Según este autor, la secularización es entendida por lo general como la separación progresiva de la civilización laica moderna de sus orígenes sagrados:

Pero, si lo sagrado natural es aquel mecanismo violento que Jesús vino a desvelar y desmentir, es muy posible que la secularización -que es también pérdida de autoridad temporal por parte de la Iglesia, autonomización de la razón humana respecto a la dependencia de un Dios absoluto, juez amenazador, de tal modo trascendente en relación con nuestras ideas del bien y del mal que parece un soberano caprichoso y extravagante- sea justamente un efecto positivo de las enseñanzas de Jesús y no un modo de alejarse de ella (Vattimo, 1999: 41).

En La lucha de los Dioses en la modernidad. Del monoteísmo religioso al politeísmo cultural, Josexto Beriain se inclina por esta interpretación y se adhiere al postulado de Weber sobre la secularización que entre sus muchas acepciones indica la generación de una sociedad sin centro, es decir, ningún subsistema social puede pretender una centralidad, y con esta idea coincide Hervieu-Léger.

Estas interpretaciones de la secularización escapan de la concepción clásica y reconsideran la relación de la religión con la modernidad. Hervieu-Léger señala que la sociología de las religiones ha comenzado a entender esta relación bajo el doble aspecto de la dispersión de las creencias y de la desregulación institucional; $\mathrm{y}$ se interesa ahora por las elaboraciones creyentes individuales, maleables, dispersas y sometidas a la lógica de los remiendos, a través de las cuales es posible introducirse en las formas de religiosidad modernas. 
La secularización no es la pérdida de la religión en el mundo moderno, sino el conjunto de los procesos de reacomodo de las creencias que se produce en una sociedad cuyo motor es la insaciabilidad de las expectaciones que suscita, y cuya condición cotidiana es la incertidumbre ligada a la búsqueda interminable de los medios para satisfacerlas (43).

Para esta autora, la secularización implica la pérdida de dominio de las instituciones religiosas, pero también la recomposición de las representaciones religiosas que han otorgado a nuestras sociedades los valores para pensarse a sí mismas como autónomas.

La modernidad, según esta autora, no ha clausurado el tema de la religión: ha inventado sus propias formas de religiosidad. $\mathrm{Y}$ no se puede omitir de este paisaje creyente la temática del remiendo, del collage, de la apropiación personal y dispersa de los contenidos de las grandes religiones históricas y las construcciones individualizadas de fe que se extienden más allá de los límites de las religiones institucionalizadas.

Se trata, entonces, de una religiosidad en movimiento. El reto del sociólogo es dar cuenta de esta movilidad y ella lo asume en este texto recurriendo a dos analogías: la del peregrino y la del convertido. El supuesto que yace en estas analogías es que las creencias tienden a diseminarse, a ajustarse cada vez menos a los modelos establecidos y a las prácticas controladas por las instituciones. En los propios términos de la autora:

La figura del convertido, en la que se inscribe los rasgos de una religiosidad en movimiento, es pues ante todo la del 'buscador espiritual' cuyo recorrido, a menudo largo y sinuoso, se estabiliza, al menos por un tiempo, en una afiliación comunitaria escogida que vale tanto como identificación personal y social como religiosa.

Es el grado de control institucional el que marca la diferencia entre el practicante regular y el peregrino, pues mientras el primero se rige por las disposiciones establecidas y obligatorias; el peregrino se maneja por una práctica voluntaria, personal que conserva su carácter de elección individual aun cuando la peregrinación tome una forma colectiva.

Si la figura del peregrino le permite dar cuenta de la religión en movimiento, la del convertido la remite al tipo de sociabilidad, a la formación de identidades religiosas a que da lugar esta movilidad. La conversión cristaliza un deseo de una vida personal puesta en orden en la que se expresa una dimensión contestataria, es decir, la entrada en una comunidad ideal opuesta a la sociedad circundante. La desregularización de la creencia va acompañada de una crisis de las identidades religiosas heredadas, favorece la búsqueda de identidades religiosas que no están plenamente conformadas, pues el individuo debe proporcionarse él mismo esa identidad.

El convertido, sostiene, es aquel individuo o grupo que pasa voluntariamente, o por coacción, de una religión a otra. Puede tratarse de un individuo o grupo que cambia de religión y rechaza o critica su religión anterior; de un individuo que no había pertenecido nunca a alguna tradición religiosa y decide reconocer una y agregarse; la del "reafiliado" o convertido desde el interior, es decir, el que redescubre una identidad religiosa. En todos estos casos de conversión se inscriben los rasgos de una religiosidad en movimiento, se 
Astrid Maribel Pinto Durán

trata del "buscador espiritual" cuya trayectoria se estabiliza por un tiempo, dentro de una comunidad religiosa elegida que le sirve como identificación.

El impulso de las conversiones toma igualmente en las religiones históricas un relieve utópico inseparable de la dinámica de la construcción de sí mismo. El convertido, señala, reorganiza su vida según las normas de la comunidad a la que ha decidido incorporarse y en la que encuentra la posibilidad de construirse a sí mismo ante la fluidez de identidades que caracteriza a las sociedades modernas en las que ningún principio adquiere centralidad para organizar la experiencia. Pone como ejemplo el caso de los jóvenes convertidos al Islam, quienes sustituyen el mito de la integración por el empleo de una salvación total por la fe. Sin fe el joven queda sujeto a la delincuencia, la droga y el desvío social. Al entrar en la fe islámica, al convertirse en un ser piadoso, al reorganizar su vida a partir de la práctica, recobra el equilibrio, encuentra la dignidad en este mundo gracias al trabajo.

A partir de estas contestaciones, HervieuLéger observa otro de los grandes supuestos que acompañan al de la secularización: el individualismo. La noción más inmediata de individualismo es la de una atomización que se produce en el seno de las sociedades modernas y remite a un aislamiento hacia el ámbito privado y a un desafecto por las cuestiones públicas y comunitarias. Autores como Barman (2004, 2005) o Lipovestky (2005), quienes se preocupan por definir los rasgos de la modernidad tardía, ven en el individualismo un despliegue antártico, una deserción o apatía social que acompaña al capitalismo, al consumismo. Los intentos de comunidad son presentados por estos autores como sueños, artefactos de la individualidad y no como fuerzas que definan las identidades.
El peregrino y el convertido. La religión en movimiento pone en tela de juicio tales afirmaciones, pues en él se sostiene que a pesar de que se ha personalizado la profesión de un credo, el individualismo religioso no impide formas de organización identitarias. Hervieu-Léger señala que el proceso de atomización individualista no imposibilita, en el terreno religioso y en el resto de la vida social, la multiplicación de comunidades fundadas sobre afinidades sociales, culturales y espirituales, sobre el compromiso voluntario de las personas.

El peregrino y el convertido remiten al movimiento por la fluidez de los recorridos espirituales individuales que pueden, bajo ciertas condiciones, organizarse como trayectorias de identificación, como formas de sociabilidad religiosa móviles y temporales. Por esta razón, la autora sugiere analizar la identidad religiosa como un resultado transitorio o fugaz, y no como una identidad sustantiva y estable.

Hervieu-léger dedica, finalmente, un espacio de reflexión en este texto a la crisis que estas formas modernas de religiosidad generan en las instituciones religiosas y analiza algunas de sus implicaciones sociales y culturales, ya que la religiosidad dócil, regular, vivida como observancia de las normas institucionales ha cedido el paso a una práctica participante. "La iglesia católica se encuentra tanto más desprotegida para hacer frente a esto cuanto que esta crisis cuestiona radicalmente la estructura jerárquica y centralizada del poder sobre el que se apoya. Pero se puede pensar que la figura del practicante afecta, de formas diversas, al conjunto de confesiones religiosas" (96).

La revisión implícita de las categorías básicas con que solemos pensar los fenómenos religiosos no es la única virtud de esta aportación de Hervieu-léger. La autora escapa a la explicación en 
boga que pretende reducir las prácticas religiosas modernas al consumismo, incluso a aquellas posturas teóricas que niegan toda posibilidad de inteligibilidad. Su propuesta es teórica y es metodológica. Valiosa aportación para todos aquellos que de alguna manera hemos sentido lo inasible de los fenómenos religiosos actuales, precisamente porque seguimos empecinados con modelos teóricos que poco se adecuan a la comprensión de una religiosidad cuya característica es el "toma y deja”, la movilidad.

\section{Bibliografía}

Bauman, Zygmunt, 2004, Modernidad líquida, Fondo de Cultura Económica, Buenos Aires, Argentina.
,2005, Amor líquido. Acerca de la fragilidad de los vinculos humanos, FCE, Argentina.

Beriain, Josetxo, 2000, La lucha de los Dioses en la modernidad. Del monoteísmo religioso al politeísmo cultural, AnthroposUniversidad pública de Navarra-Universidad Central de Venezuela, Barcelona

Lipovetsky, Pilles, 2005, El crepúsculo del deber. La ética indolora de los nuevos tiempos democráticos, Anagrama, Barcelona.

Lyons, David, 2000, Jesús, Disneylandia. La religión en la posmodernidad, Catedra, Madrid.

Vattimo, Gianni, 1999, Creer que se cree, Paidós Studio, España.

Weber, Max, 1983 (vol.1), 1987 (vol. II), 1988 (vol. III), Ensayos sobre sociología de la Religión, Taurus, Madrid.

Astrid Maribel Pinto Durán CESMECA-UNICACH 